\title{
Help-seeking intentions for early signs of mental illness and their associated factors: comparison across four kinds of health problems
}

Machi Suka ${ }^{*}$, Takashi Yamauchi ${ }^{2}$ and Hiroki Sugimori ${ }^{3}$

\begin{abstract}
Background: Failure and delay in initial treatment contact for mental disorders has been recognized as an important public health problem. According to the concept of mental health literacy, recognition of symptoms is crucial to making decisions to seek or not seek professional help. The aims of this study were to investigate the types of health problems for which Japanese adults intend to seek help, their preferred sources of help, and the factors associated with help-seeking intentions.
\end{abstract}

Methods: A cross-sectional web-based survey was conducted in June 2014 among Japanese adults aged 20-59 years. A total of 3308 eligible respondents were included in this study. Help-seeking intentions were measured by listing potential sources of help (including 'would not receive help') and asking which ones would be chosen in four health conditions indicated by irritability, dizziness, insomnia, and depressed mood, respectively.

Results: In the case of dizziness, $85.9 \%$ of the participants reported a positive help-seeking intention and $42.7 \%$ gave first priority to seeking help from formal sources. These percentages were smaller in the cases of insomnia (75.4 and $25.0 \%$ ), depressed mood (74.9 and $18.7 \%$ ), and irritability (72.9 and $0.9 \%$ ). Multiple logistic regression analysis revealed that the factors significantly associated with help-seeking intentions were almost identical across the four health problems. In particular, perception of family and friends regarding help-seeking, psychiatric history, contact with people with mental illness, better health literacy, and neighborhood communicativeness were significantly associated with the overall help-seeking intention and also the help-seeking intention from formal sources for all the problems of dizziness, insomnia, and depressed mood.

Conclusions: The majority of participants indicated their intentions to seek help, but psychological problems (insomnia and depressed mood) were less likely to induce help-seeking intentions than a physical problem (dizziness). Besides developing health literacy skills, community-based interventions for creating a friendly approachable atmosphere and facilitating daily interactions with family, friends, and neighbors may be worth considering as a possible public health strategy for encouraging help-seeking whether for psychological or physical problems.

Keywords: Help-seeking, Mental health, Questionnaire survey

\footnotetext{
* Correspondence: suka@jikei.ac.jp

${ }^{1}$ Department of Public Health and Environmental Medicine, The Jikei

University School of Medicine, 3-25-8 Nishi-Shimbashi, Minato-ku, Tokyo

105-8461, Japan

Full list of author information is available at the end of the article
}

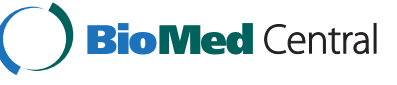

C 2016 Suka et al. Open Access This article is distributed under the terms of the Creative Commons Attribution 4.0 International License (http://creativecommons.org/licenses/by/4.0/), which permits unrestricted use, distribution, and reproduction in any medium, provided you give appropriate credit to the original author(s) and the source, provide a link to the Creative Commons license, and indicate if changes were made. The Creative Commons Public Domain Dedication waiver (http://creativecommons.org/publicdomain/zero/1.0/) applies to the data made available in this article, unless otherwise stated. 


\section{Background}

The Global Burden of Disease Study 2013 [1] revealed that mental and substance abuse disorders accounted for $21.2 \%$ of years lived with disability (YLDs). Major depressive disorder was a crucial contributor in both developed and developing countries: it is the leading cause of YLDs in 56 countries, the second leading cause in 56 countries, and the third leading cause in 34 countries. There is now a variety of effective treatments available for mental disorders. To prevent negative sequelae of mental disorders, prompt initial contact with healthcare providers is needed after first onset of symptoms. However, many affected individuals in both developed and developing countries delay in seeking professional help and fail to receive effective treatment $[2,3]$.

Jorm et al. have coined the term "mental health literacy" with the definition "knowledge and beliefs about mental disorders which aid their recognition, management or prevention" [4]. According to the concept of mental health literacy, recognition of symptoms is crucial to making decisions to seek or not seek professional help [5]. Signs and symptoms of mental illness include a variety of psychological as well as somatic symptoms. As for patients with depression in primary care, approximately two thirds of the patients present with somatic symptoms [6]. People who begin to exhibit a symptom of mental illness should recognize the early signs and take prompt action to recover their own health. Unfortunately, a number of population surveys have revealed that many people cannot correctly recognize symptoms depicted in a vignette as a mental disorder [5]. If people do not recognize the signs and symptoms of mental illness, they will not seek help, and thus healthcare services will be ineffective regardless of their availability.

People who should receive professional help are not limited to those who meet the diagnostic criteria from the Diagnostic and Statistical Manual of Mental Disorders (DSM). In order to encourage early helpseeking for mental illness, policymakers need to understand what kinds of early signs of mental illness are less likely to induce help-seeking behavior. Previous studies have revealed that the majority of patients who were diagnosed with major depressive disorder had reported only somatic symptoms as the reason for visiting the physician [6]. This indicates that patients with depression in primary care tend to report somatic symptoms more readily than they report psychological symptoms. Unfortunately, most of the previous studies have been conducted among clinical populations, i.e. patients who visited their physicians to seek help. It has been reported that the likelihood of seeking help varied depending on the type of disorder $[7,8]$. However, to our knowledge, there have been no attempts to identify differences in seeking help for different kinds of symptoms of mental illness. It remains unknown how much more likely people are to seek help for somatic symptoms as compare to psychological symptoms. Such symptom-based approaches may provide useful information for dealing with the problem of failure and delay in initial treatment contact after first onset of symptoms.

Japan has achieved universal health coverage, which provides relative equality of access to healthcare services [9]. Despite having the universal healthcare system, failure and delay in initial treatment contact for mental disorders has been recognized as an important public health problem in Japan [2, 3]. A comparative survey between Japan and the United States [10] indicated that Japanese people exhibited greater reluctance to seek professional help. A comparative survey between Japan and Australia [11] indicated that Japanese people were more reluctant to use psychiatric labels, more reluctant to discuss mental illness with others outside the family, and less positive about the benefits of seeking professional help. An international study as well as other crosscultural comparative studies suggested that the experience of symptoms varies little across countries and cultures, whereas the reporting of symptoms can be influenced by sociocultural factors, particularly stigma surrounding mental illness [12-14] These findings suggest that the public beliefs about mental illness and its treatment may contribute to failure and delay in initial treatment contact. Unfortunately, only a few studies have addressed help-seeking behavior of Japanese people, [15-17] and very little is known about the barriers and facilitators of seeking professional help in Japan. Previous studies in different countries have proposed a variety of factors that may influence help-seeking behavior for mental illness, including physical dysfunction, [18] psychological distress, [18] exposure to mental illness, [19-21] knowledge about mental illness, [22] stigmatizing attitudes to mental illness, [20, 21] perceived effectiveness of professional help, [23] social network, [24] and neighborhood context [25] In order to develop public health strategies for encouraging helpseeking for mental illness, policymakers need to have a clear understanding of help-seeking behavior of their target population groups and to identify the factors that will have a significant impact on their helpseeking behavior.

The aims of this study were to investigate the types of health problems for which Japanese adults intend to seek help, their preferred sources of help, and the factors associated with help-seeking intentions. The study participants were asked their intentions to seek help in four health conditions indicated by irritability, dizziness, insomnia, and depressive mood, respectively. A variety of factors mentioned above were examined for their 
associations with help-seeking intentions. In contrast to previous studies that examined help-seeking intentions for specific mental disorders, $[7,8]$ this study focused on early signs that could appear before it is officially diagnosed as major depressive disorder [6, 26]. Depressed mood and insomnia are included in the DSM-5 diagnostic criteria for major depressive disorder [26]. Dizziness and irritability are not part of the diagnostic criteria but are most commonly reported symptoms in patients with depression in primary care [6]. A follow-up study of Japanese workers suggested that dizziness, as well as loss of interest, may be a significant predictor of depression [27]. Recent studies on the significance of irritability in major depressive disorder in adults suggested that irritability may serve as a severity marker, $[28,29]$ or a subtyping distinction $[29,30]$. We believe the findings of this study will provide a new direction for public health strategies for encouraging help-seeking for mental illness as well as contribute to a better understanding of helpseeking behavior of Japanese people.

\section{Methods}

Participants

A cross-sectional web-based survey was conducted in June 2014 among Japanese adults aged 20-59 years. Details of the survey have been presented elsewhere [31]. Briefly, participants in the survey were recruited from an online research panel of a a leading research company in Japan (INTAGE, INC., Tokyo, Japan). Students and medical professionals were excluded from recruitment, because their attitudes to help-seeking seem different in kind from that of lay people [32, 33]. Recruitment emails were sent to 8721 randomly selected eligible registrants, and applicants for participation in the survey were accepted in the order of receipt until the number of participants reached the quotas (100 people for each age/gender/prefecture stratum). All participants voluntarily agreed to participate in the survey after reading a description of the purpose and procedure of the survey. Consent to participate was implied by the completion and submission of the survey.

A total of 3365 responses were obtained over 8 days of recruitment. Of these, 51 people provided incomplete or inconsistent answers to questions. Six people reported having the following diseases that affected their activities of daily living at the time of the survey: stroke, epilepsy, syringomyelia, multiple sclerosis, nerve palsy, and chronic thyroiditis. People with such diseases were excluded because of how these diseases can impair helpseeking decision making by presenting practical barriers to access and utilization of healthcare services. The remaining 3308 participants were finally included in this study. Table 1 shows the characteristics of the study participants. According to the 2010 national census, [34]
Table 1 Characteristics of the study participants

\begin{tabular}{|c|c|c|c|}
\hline & & $\mathrm{N}$ & \\
\hline \multirow[t]{2}{*}{ Gender } & Male & 1621 & $49.0 \%$ \\
\hline & Female & 1687 & $51.0 \%$ \\
\hline \multirow[t]{4}{*}{ Age } & 20-29 years & 797 & $24.1 \%$ \\
\hline & $30-39$ & 842 & $25.5 \%$ \\
\hline & $40-49$ & 837 & $25.3 \%$ \\
\hline & $50-59$ & 832 & $25.2 \%$ \\
\hline \multirow[t]{3}{*}{ Education } & High school & 1066 & $32.2 \%$ \\
\hline & Junior college/vocational school & 905 & $27.4 \%$ \\
\hline & University/graduate school & 1337 & $40.4 \%$ \\
\hline \multirow[t]{3}{*}{ Marital status } & Married & 1960 & $59.3 \%$ \\
\hline & Unmarried & 1184 & $35.8 \%$ \\
\hline & Divorced/widowed & 164 & $5.0 \%$ \\
\hline \multirow[t]{3}{*}{ Occupation } & No occupation & 770 & $23.3 \%$ \\
\hline & Temporary or part-time job & 560 & $16.9 \%$ \\
\hline & Full-time job & 1978 & $59.8 \%$ \\
\hline \multirow[t]{6}{*}{ Household income } & $<2.0$ million yen ${ }^{a}$ & 363 & $11.0 \%$ \\
\hline & 2.0-3.9 million & 777 & $23.5 \%$ \\
\hline & 4.0-5.9 million & 937 & $28.3 \%$ \\
\hline & 6.0-7.9 million & 618 & $18.7 \%$ \\
\hline & 8.0-9.9 million & 347 & $10.5 \%$ \\
\hline & 10.0+ million & 266 & $8.0 \%$ \\
\hline \multirow[t]{2}{*}{ Medical condition } & No disease & 2449 & $73.6 \%$ \\
\hline & Any disease & 879 & $26.4 \%$ \\
\hline
\end{tabular}

${ }^{a}$ One million yen was about 10,000 U.S. dollars at the time of the survey

the percentage of the Japanese population aged 20-59 years with university degrees was $21.9 \%$, considerably lower than that of this study (40.4\%), whereas the percentages of married and employed population were 58.2 and $72.7 \%$, respectively, almost equal to that of this study (59.3 and $76.7 \%$, respectively).

The study protocol was approved by the ethics committee of the Jikei University School of Medicine and has been conducted in accordance with the Ethical Guidelines for Epidemiological Studies by the Japanese Government.

\section{Measures}

The questionnaire asked about problem-specific helpseeking intentions, medical conditions, psychological well-being, exposure to mental illness, health literacy, stigmatizing attitudes to mental illness, perceived effectiveness of professional help, social network, and neighborhood context. The eight factors that may influence help-seeking behavior for mental illness were derived from the literature [18-25]. The components of the questionnaire relevant to this study are detailed below. 


\section{Problem-specific help-seeking intentions}

A literature review [35] reported that help-seeking has been defined and measured inconsistently across studies in the mental health context. In the absence of consensus on definition and measurement of help-seeking, intentions to seek help for mental health problems are often measured by listing potential sources of help and asking which ones would be chosen in a specified health condition [35-38]. This commonly used methodology was adopted for this study.

Participants were asked what they would do if they were in four health conditions indicated by irritability, dizziness, insomnia, and depressed mood, respectively: every day for more than 2 weeks, 1) you were irritated by trouble in your neighborhood (irritability); 2) you had severe dizziness, often accompanied by nausea (dizziness); 3) you could not sleep well at night despite being tired (insomnia); and 4) you felt so depressed all day that it was difficult to function (depressed mood). According to the DSM-5 diagnostic criteria for major depressive disorder, [26] the time period of 2 weeks was applied to all the health problems. Table 2 shows an overview of the four health problems presented in the questionnaire. The four health problems were designed so as to have different features. Two psychological symptoms and two somatic symptoms were selected from among most commonly reported symptoms in patients with depression in primary care [6]. Compared to depressed mood and insomnia that are included in the DSM-5 diagnostic criteria for major depressive disorder, [26] dizziness is more often caused by physical problems [39]. The irritability problem of this study was supposed to be triggered by an obvious non-medical problem (i.e. neighborhood trouble), so that help from medical professionals was not always necessary for this health problem. Our recent study revealed that tendency to consult about everyday affairs is a key player in help-seeking decision-making for mental illness [17]. Participants who reported a positive help-seeking intention for the irritability problem could be considered as those having a tendency to consult about everyday affairs.

All four health problems were presented to each participant one at a time in random order. Respondents chose all agreeable options for each health problem and

Table 2 Overview of the four health problems presented in the questionnaire

\begin{tabular}{lll}
\hline Health problem & Type of symptom & $\begin{array}{l}\text { Most probable cause } \\
\text { (or trigger) }\end{array}$ \\
\hline Irritability & Psychological symptom & Non-medical problem \\
Dizziness & Somatic symptom & Physical problem \\
Insomnia & Somatic symptom & Mental problem \\
Depressed mood & Psychological symptom & Mental problem \\
\hline
\end{tabular}

also marked the option that they gave first priority. The options were 1) consult with my family or relative, 2) consult with my friend, 3) consult with my colleague, 4) see a health professional at my workplace, 5) see a medical professional at any hospital, 6) use a common consultation service provided by a public or private institution, 7) seek advice on the Internet, 8) seek advice from the other sources, 9) would not receive help from others because I felt it impossible to seek help for some reason, and 10) would not receive help from others because I feel no need for help. To prepare the potential sources of help options, we reviewed the literature relevant to this topic and selected appropriate ones in consideration of Japanese healthcare system [9]. We sought comments on the draft version from some lay people and then completed the final version.

In addition to their intentions to seek help, participants were asked to rate how likely their family and friends would think that they should 1) receive help from others and 2) see a medical professional, respectively for each health problem.

In reply to the question about their help-seeking intention, those who chose the options of 4)-5) were counted as having positive help-seeking intentions from formal sources, and those who chose the options of 1)-3) 6)-8) were counted as having positive helpseeking intentions from informal sources. Those who chose the options of 9)-10) were counted as having no help-seeking intention, and they were additionally asked the reason why they would not seek help from others for the health problem.

\section{Medical condition}

Participants were asked to report whether they had any chronic disease for which they were undergoing medical treatment. The list included hypertension, diabetes, dyslipidemia, stroke, heart trouble, renal failure, cancer, insomnia, depression, and others.

\section{Psychological well-being}

The World Health Organization Five Well-Being Index (WHO-5) [40, 41] was used to measure psychological well-being. Respondents choose one of 6 options (scored 0-5 points) in response to each of the 5 statements. The WHO- 5 score is calculated by totaling the scores of the five responses, ranging between 0 and 25 points with high scores indicating better well-being.

\section{Exposure to mental illness}

Psychiatric history was assessed using the following question: have you ever seen a medical professional for your mental health problem? Those who gave an affirmative response were counted as having used mental health services. 
The Reported and Intended Behaviour Scale (RIBS) [42] was used to determine the extent of contact with people with mental illness. The first subscale consists of four questions about living with, working with, living nearby, and having a close friendship with people with mental illness, either at present or in the past. Those who answered 'yes' to at least one question were counted as having had contact with people with mental illness.

\section{Health literacy}

Health literacy is originally defined as the cognitive and social skills which determine the motivation and ability of individuals to gain access to, understand, and use information in ways which promote and maintain good health [43]. On the basis of our previous findings that people with adequate health literacy tend to choose healthy behavior, [44] we hypothesized that people with adequate health literacy are more likely to seek help for any health problem (whether for physical or mental disorders). Suka et al. developed a generic health literacy measure for Japanese adults, named the 14-item Health Literacy Scale (HLS-14) [45]. Because of dealing with various types of health problems, we decided to use the generic health literacy measure rather than specific measures in this study.

The HLS-14 consists of 5 items for functional literacy, 5 items for communicative literacy, and 4 items for critical literacy. Respondents choose one of 5 options (scored 1-5 points) in response to each of the 14 statements. The HLS-14 score is calculated by totaling the scores of the 14 responses, ranging between 14 and 70 points, with high scores indicating better health literacy.

\section{Stigmatizing attitudes to mental illness}

Referring to the questionnaire for the Eurobarometer 64.4 survey, [46] four stigmatizing attitudes to mental illness were assessed using the following statements, respectively on a 4-point scale: people with mental illness 1) constitute a danger to others (dangerous); 2) are unpredictable; 3) have themselves to blame (blameworthy); and 4) never recover. For reference, the Cronbach alpha of this scale was 0.68 in this study, which reached the minimally acceptable level of internal consistency $(\geq 0.65)$ [47]. For analysis, the responses were dichotomized into positive (strongly agree/agree) and negative (disagree/strongly disagree).

\section{Perceived effectiveness of professional help}

Referring to the questionnaires for the World Mental Health Survey (WMH) Initiative Version of the World Health Organization (WHO) Composite International Diagnostic Interview (CIDI) Part II, [48] perceived effectiveness of professional help was measured using the following two questions: 1) of the people who see a professional for serious mental illness, what percent do you think are helped? (range $0-100 \%$ ); 2) of those with serious mental illness who do not get professional help, what percent do you think get better even without it? (range 0-100\%). The responses to the first question showed a normal distribution with a mean of 48.2 (SD 23.6) and a median of 50. The responses to the second question showed a right-skewed distribution with a mean of 27.0 (SD 21.0) and a median of 20. To obtain a single index value for perceived effectiveness of professional help, the percentages on the two questions were subtracted (the first question minus the second question), with high values indicating more positive perception of the effectiveness of professional help $[17,23,31]$. The calculated values, showing a leftskewed distribution with a mean of 21.2 (SD 29.7) and a median of 20 , were trichotomized into positive $(1<\%$, better than no help), neutral ( $0 \%$, equal to no help), and negative $(<-1 \%$, worse than no help). Participants were also asked whether they would be embarrassed if their friends knew they were getting professional help for mental illness.

\section{Social network}

The abbreviated Lubben Social Network Scale (LSNS-6) $[49,50]$ was used to measure social network. This scale consists of 3 questions for family ties and 3 questions for friendship ties. Respondents choose one of 6 options (scored 1-6 points) in response to each of the 6 questions. The LSNS-6 score is calculated by totaling the scores of the 6 responses, ranging between 6 and 36 points, with high scores indicating greater ties to family and friends.

\section{Neighborhood context}

Neighborhood is characterized as a geographically localized community often with face-to-face interactions among members. Referring to the questionnaire for the Health Survey of People Affected by the Great East Japan Earthquake, [51] four specific features of neighborhood context relevant to neighborhood social capital were assessed using the following statements, respectively on a 5-point scale: people in your neighborhood 1) say hello whenever they pass each other (communicative); 2) trust in each other (trustful); 3) help each other (helpful); and 4) work together to solve neighborhood problems (cooperative). For reference, the Cronbach alpha of this scale was 0.87 in this study, which reached the minimally acceptable level of internal consistency $(\geq 0.65)$ [47]. For analysis, the responses were dichotomized into positive (strongly agree/agree) and negative (not sure/disagree/strongly disagree). 


\section{Statistical Analysis}

The percentages of participants reporting a positive help-seeking intention for each health problem were compared using Chi-square test. McNemar test was used to assess the significance of the difference between the two correlated proportions. Multiple logistic regression was used to identify factors independently associated with the help-seeking intention for each health problem. Adjusted odds ratios (ORs) and $95 \%$ confidence intervals (CIs) were calculated for the overall help-seeking intention (whether from formal or informal sources) and that limited to formal sources, respectively. The analysis of help-seeking intention from formal sources was not performed for irritability, because help from formal sources seems not always necessary for this health problem. All statistical analyses were performed using SAS ver.9.4 software (SAS Institute, Cary, NC). Significant levels were set at $p<0.05$.

\section{Results}

Table 3 shows the percentages of participants reporting a positive help-seeking intention for the four health problems. In the case of dizziness, $85.9 \%$ of the participants were recognized as having a positive help-seeking intention; $67.8 \%$ reported that they would seek help from formal sources at any time; and $42.7 \%$ gave first priority to seeking help from formal sources. These percentages were smaller in the cases of irritability, insomnia, and depressed mood, and the smallest values were found in the case of irritability. McNemar test was performed to compare the percentages of participants reporting a positive help-seeking intention for each pair of health problems. Significant differences were found between all pairs of the health problems except the comparison between insomnia and depressed mood $(p=0.405)$.

Table 4 shows the comparisons of percentages of participants reporting a positive help-seeking intention. Most of the variables of interest showed significant associations with the help-seeking intention for all the health problems in univariate analyses.

Table 5 shows the results of multiple logistic regression analysis for the overall help-seeking intention. Perception of family and friends regarding help-seeking (their family and friends would think that they should receive help from others for the problem) showed the strongest association with the help-seeking intention for all the health problems. Besides this, the following factors were significantly associated with the help-seeking intention for all the health problems: female gender, unmarried status, psychiatric history, contact with people with mental illness, higher HLS-14 scores, higher LSNS-6 scores, and one of the neighborhood contexts (communicative).

Table 6 shows the results of multiple logistic regression analysis for help-seeking intention from formal sources. Although the perception of family and friends was significantly associated with help-seeking intention from formal sources, the effect-sizes were lower than its association with overall help-seeking intention. Besides this, the following factors were significantly associated with the help-seeking intention for all the health problems: presence of any disease, psychiatric history, contact with people with mental illness, higher HLS-14 scores, one of the stigmatizing attitudes to mental illness (blameworthy), positive perception of the effectiveness of professional help, and one of the neighborhood contexts (communicative).

Table 7 shows the major reason for no help-seeking intention for the four health problems. Of the participants reporting no help-seeking intention, those who had hoped to receive help accounted for 35.7 \% (321/ 898) for irritability, $23.9 \%(111 / 465)$ for dizziness, $29.6 \%(241 / 813)$ for insomnia, and $41.2 \%(342 / 831)$ for depressed mood. The most frequently cited reason for no help-seeking intention for irritability was lack of awareness of potential sources of help. That for dizziness was willingness to handle the problem by oneself. For insomnia and depressed mood, negative perception of the effectiveness of help, lack of awareness of potential sources of help, and willingness to handle the problem by oneself were the three most frequent reasons for no help-seeking intention. On the other hand, when the reasons why they would avoid seeking help from formal sources were asked, the most frequently cited one was lack of awareness of potential sources of help for all of the problems of dizziness, insomnia, and depressed mood.

\section{Discussion}

This study examined the help-seeking intentions for four kinds of health problems and their associated factors at the individual and neighborhood levels among Japanese

Table 3 Intentions to seek help for four health problems

\begin{tabular}{|c|c|c|c|c|c|c|c|c|c|}
\hline \multirow[b]{2}{*}{ Help from formal sources } & \multirow[b]{2}{*}{ One of the choices } & \multicolumn{2}{|c|}{ Irritability } & \multicolumn{2}{|c|}{ Dizziness } & \multicolumn{2}{|c|}{ Insomnia } & \multicolumn{2}{|c|}{ Depressed mood } \\
\hline & & 78 & $2.4 \%$ & 2244 & $67.8 \%$ & 1522 & $46.0 \%$ & 1269 & $38.4 \%$ \\
\hline & First choice & 31 & $0.9 \%$ & 1414 & $42.7 \%$ & 827 & $25.0 \%$ & 620 & $18.7 \%$ \\
\hline \multirow[t]{2}{*}{ Help from informal sources } & One of the choices & 2387 & $72.2 \%$ & 1808 & $54.7 \%$ & 1877 & $56.7 \%$ & 2041 & $61.7 \%$ \\
\hline & First choice & 2379 & $71.9 \%$ & 1429 & $43.2 \%$ & 1668 & $50.4 \%$ & 1857 & $56.1 \%$ \\
\hline No help-seeking intention & & 898 & $27.1 \%$ & 465 & $14.1 \%$ & 813 & $24.6 \%$ & 831 & $25.1 \%$ \\
\hline
\end{tabular}


Table 4 Percentages of subjects reporting a positive help-seeking intention

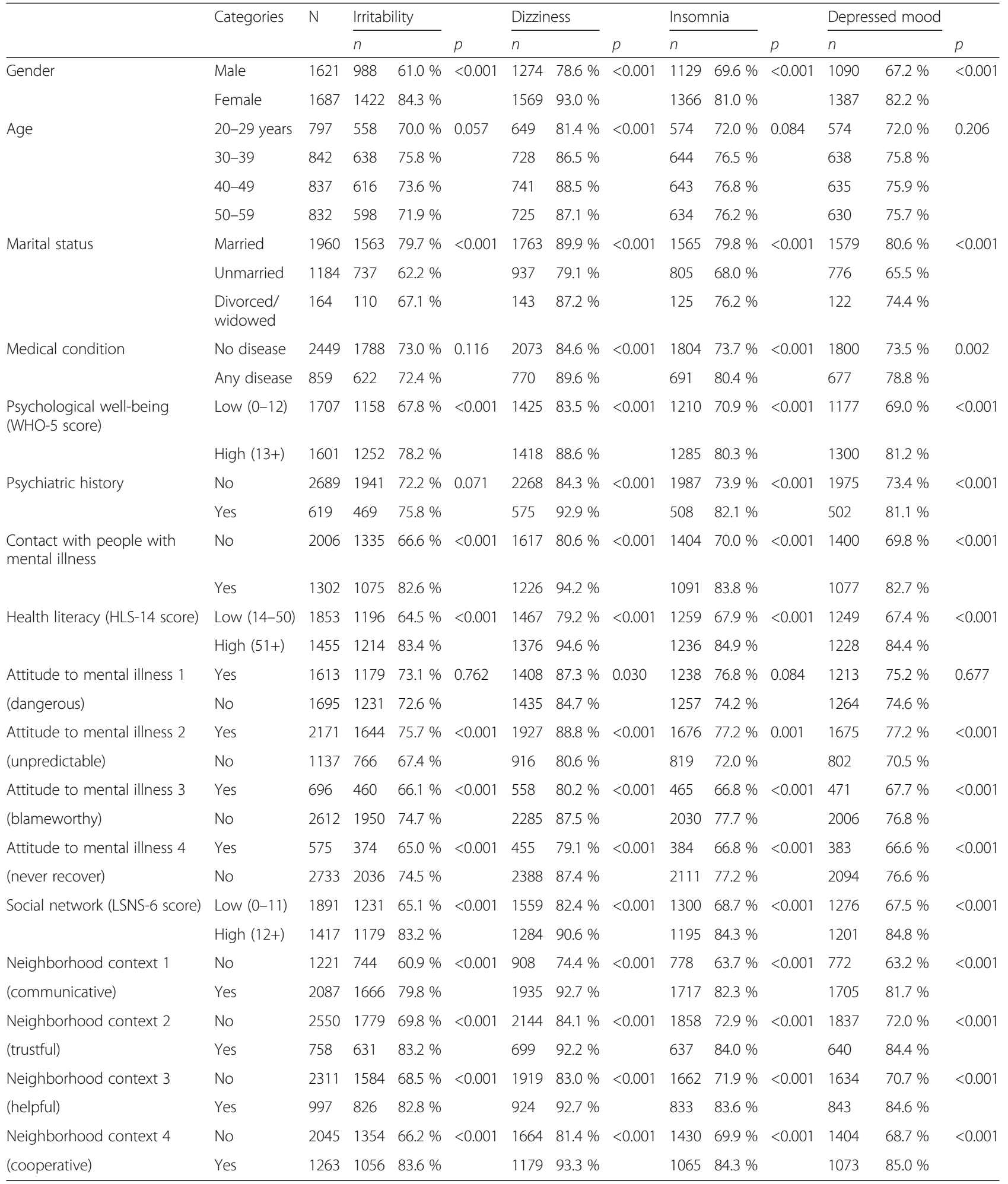

adults. In contrast to previous studies that examined help-seeking intentions for specific mental disorders, $[7,8]$ this study focused on early signs that could appear before it is officially diagnosed as major depressive disorder. The four health problems presented in the questionnaire were designed so as to represent common signs and symptoms of depression. Our symptom-based approach may provide useful information for dealing with 
Table 5 Factors related to overall help-seeking intention

\begin{tabular}{|c|c|c|c|c|c|c|c|c|c|}
\hline & \multirow[t]{2}{*}{ Category } & \multicolumn{2}{|c|}{ Irritability } & \multicolumn{2}{|c|}{ Dizziness } & \multicolumn{2}{|c|}{ Insomnia } & \multicolumn{2}{|c|}{ Depressed mood } \\
\hline & & $\mathrm{OR}$ & $(95 \% \mathrm{Cl})$ & $\mathrm{OR}$ & $(95 \% \mathrm{Cl})$ & $\mathrm{OR}$ & $(95 \% \mathrm{Cl})$ & $\mathrm{OR}$ & $(95 \% \mathrm{Cl})$ \\
\hline Gender & Female & 2.40 & $(1.99-2.89)$ & $\underline{2.17}$ & $(1.68-2.81)$ & 1.26 & $(1.04-1.53)$ & 1.58 & $(1.31-1.91)$ \\
\hline Age & plus 1 year & 0.98 & $(0.97-0.99)$ & 0.99 & $(0.99-1.01)$ & 0.99 & $(0.98-1.00)$ & 0.99 & $(0.98-1.00)$ \\
\hline Marital status & Unmarried & $\underline{0.58}$ & $(0.47-0.72)$ & $\underline{0.71}$ & $(0.54-0.93)$ & $\underline{0.75}$ & $(0.60-0.93)$ & $\underline{0.63}$ & $(0.51-0.79)$ \\
\hline Medical condition & Any disease & 0.99 & $(0.80-1.24)$ & 1.22 & $(0.90-1.67)$ & 1.49 & $(1.18-1.89)$ & 1.38 & $(1.09-1.73)$ \\
\hline Psychological well-being (WHO-5 score) & plus 1 point & 1.02 & $(1.01-1.04)$ & 1.02 & $(0.99-1.04)$ & 1.03 & $(1.01-1.05)$ & 1.04 & $(1.03-1.06)$ \\
\hline Psychiatric history & Yes & 1.43 & $(1.11-1.84)$ & $\underline{2.87}$ & $(1.94-4.25)$ & 1.84 & $(1.40-2.41)$ & 1.87 & $(1.43-2.45)$ \\
\hline Contact with people with mental illness & Yes & 1.72 & $(1.41-2.10)$ & $\underline{2.02}$ & $(1.51-2.70)$ & 1.36 & $(1.10-1.67)$ & 1.38 & $(1.13-1.69)$ \\
\hline Health literacy (HLS-14 score) & plus 1 point & 1.04 & $(1.02-1.05)$ & 1.04 & $(1.02-1.07)$ & 1.03 & $(1.01-1.04)$ & 1.02 & $(1.00-1.03)$ \\
\hline Attitude to mental illness 1 (dangerous) & No & 1.24 & $(0.99-1.55)$ & 1.14 & $(0.84-1.54)$ & $\underline{0.87}$ & $(0.69-0.90)$ & 1.14 & $(0.90-1.42)$ \\
\hline Attitude to mental illness 2 (unpredictable) & No & $\underline{0.72}$ & $(0.57-0.90)$ & $\underline{0.60}$ & $(0.45-0.82)$ & 0.95 & $(0.75-1.20)$ & $\underline{0.77}$ & $(0.61-0.98)$ \\
\hline Attitude to mental illness 3 (blameworthy) & No & 1.23 & $(0.97-1.54)$ & 1.28 & $(0.95-1.71)$ & 1.39 & $(1.10-1.76)$ & $\underline{1.33}$ & $(1.05-1.67)$ \\
\hline Attitude to mental illness 4 (never recover) & No & 1.17 & $(0.92-1.50)$ & 1.50 & $(1.10-2.05)$ & 1.28 & $(0.99-1.65)$ & 1.21 & $(0.94-1.55)$ \\
\hline Social network (LSNS-6 score) & plus 1 point & 1.06 & $(1.04-1.08)$ & 1.04 & $(1.01-1.06)$ & 1.06 & $(1.04-1.08)$ & $\underline{1.06}$ & $(1.04-1.08)$ \\
\hline Neighborhood context 1 (communicative) & Yes & 1.24 & $(1.01-1.52)$ & $\underline{2.22}$ & $(1.68-2.92)$ & 1.38 & $(1.11-1.71)$ & 1.26 & $(1.02-1.55)$ \\
\hline Neighborhood context 2 (trustful) & Yes & 1.32 & $(0.97-1.79)$ & 1.06 & $(0.69-1.63)$ & 1.11 & $(0.82-1.52)$ & 1.21 & $(0.88-1.65)$ \\
\hline Neighborhood context 3 (helpful) & Yes & 0.88 & $(0.65-1.19)$ & 0.82 & $(0.54-1.27)$ & 0.89 & $(0.65-1.22)$ & 0.95 & $(0.69-1.28)$ \\
\hline Neighborhood context 4 (cooperative) & Yes & 1.28 & $(0.99-1.64)$ & 1.27 & $(0.89-1.81)$ & 1.12 & $(0.87-1.45)$ & 1.23 & $(0.95-1.58)$ \\
\hline Perception of family and friends & Positive & 3.37 & $(2.80-4.06)$ & 5.07 & $(3.95-6.51)$ & 5.04 & $(4.16-6.10)$ & 3.97 & $(3.29-4.80)$ \\
\hline
\end{tabular}

$O R$ adjusted odds ratio, $\mathrm{Cl}$ confidence interval

Significant odds ratios $(p<0.05)$ are underlined

Table 6 Factors related to help-seeking intention from formal sources

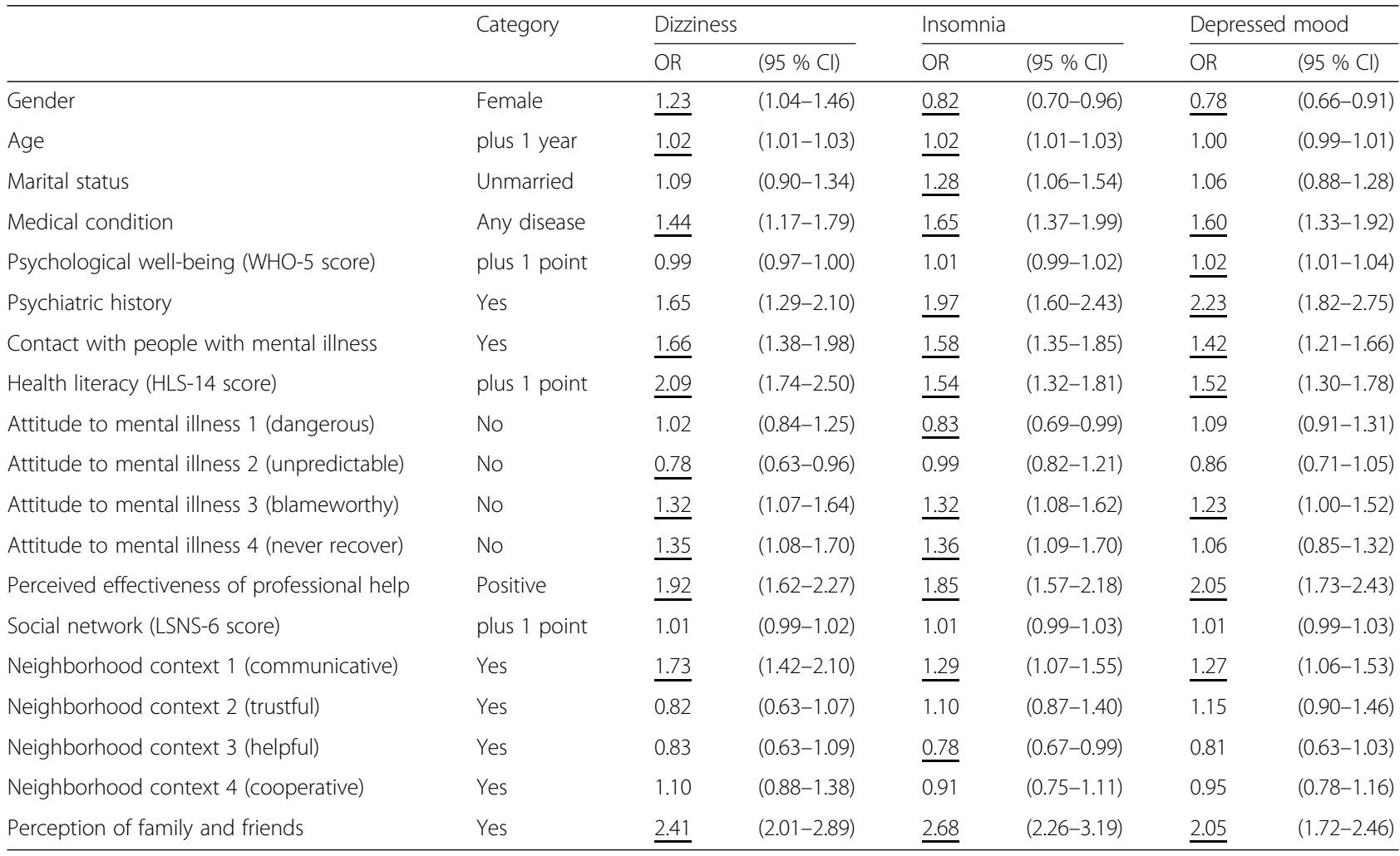


Table 7 Major reason for no help-seeking intention for four health problems

\begin{tabular}{|c|c|c|c|c|c|c|c|c|}
\hline & \multicolumn{2}{|c|}{ Irritability } & \multicolumn{2}{|c|}{ Dizziness } & \multicolumn{2}{|c|}{ Insomnia } & \multicolumn{2}{|c|}{ Depressed mood } \\
\hline I feel no need to receive help so I will not. & 577 & & 354 & & 572 & & 489 & \\
\hline I hope to receive help but I will not, because..... & 321 & & 111 & & 241 & & 342 & \\
\hline I don't have time. & 7 & $2.2 \%$ & 1 & $0.9 \%$ & 5 & $2.1 \%$ & 5 & $1.5 \%$ \\
\hline There is no place to get appropriate help. & 53 & $16.5 \%$ & 13 & $11.7 \%$ & 22 & $9.1 \%$ & 47 & $13.7 \%$ \\
\hline I am unsure where to go for help. & 55 & $17.1 \%$ & 10 & $9.0 \%$ & 24 & $10.0 \%$ & 39 & $11.4 \%$ \\
\hline I don't know how to get appropriate help. & 1 & $0.3 \%$ & 0 & $0.0 \%$ & 2 & $0.8 \%$ & 1 & $0.3 \%$ \\
\hline The place is difficult to access. & 0 & $0.0 \%$ & 1 & $0.9 \%$ & 0 & $0.0 \%$ & 1 & $0.3 \%$ \\
\hline I am concerned about the cost. & 3 & $0.9 \%$ & 7 & $6.3 \%$ & 4 & $1.7 \%$ & 5 & $1.5 \%$ \\
\hline I think it hard to talk about such a personal problem. & 27 & $8.4 \%$ & 8 & $7.2 \%$ & 15 & $6.2 \%$ & 32 & $9.4 \%$ \\
\hline People could not understand me. & 16 & $5.0 \%$ & 7 & $6.3 \%$ & 22 & $9.1 \%$ & 41 & $12.0 \%$ \\
\hline I would not be satisfied with available help. & 26 & $8.1 \%$ & 7 & $6.3 \%$ & 31 & $12.9 \%$ & 24 & $7.0 \%$ \\
\hline Available help would not do any good. & 36 & $11.2 \%$ & 6 & $5.4 \%$ & 39 & $16.2 \%$ & 50 & $14.6 \%$ \\
\hline I am concerned about what people might think if I sought help. & 13 & $4.0 \%$ & 5 & $4.5 \%$ & 3 & $1.2 \%$ & 8 & $2.3 \%$ \\
\hline I am afraid of revealing personal secrets. & 15 & $4.7 \%$ & 2 & $1.8 \%$ & 3 & $1.2 \%$ & 6 & $1.8 \%$ \\
\hline I am afraid of being treated against my will. & 0 & $0.0 \%$ & 1 & $0.9 \%$ & 1 & $0.4 \%$ & 0 & $0.0 \%$ \\
\hline I want to handle the problem on my own. & 29 & $9.0 \%$ & 21 & $18.9 \%$ & 34 & $14.1 \%$ & 42 & $12.3 \%$ \\
\hline I think the problem will get better by itself. & 7 & $2.2 \%$ & 7 & $6.3 \%$ & 16 & $6.6 \%$ & 14 & $4.1 \%$ \\
\hline Other & 33 & $10.3 \%$ & 15 & $13.5 \%$ & 20 & $8.3 \%$ & 27 & $7.9 \%$ \\
\hline
\end{tabular}

the problem of failure and delay in initial treatment contact after first onset of symptoms.

When the four health conditions indicated by irritability, dizziness, insomnia, and depressed mood were presented, the majority of participants recognized that helpseeking would be useful for solving the health problems and thus indicated their intentions to seek help. The greatest percentage of participants reporting a positive help-seeking intention was found for dizziness (physical problem), followed by insomnia (psychological problem), depressed mood (psychological problem), and irritability (non-medical problem). A similar result was obtained from the analysis for help-seeking intention from formal sources. These results indicated that psychological problems were less likely to induce help-seeking than a physical problem. Surprisingly, the likelihood of help-seeking for psychological problems was not greater than that for a non-medical problem. Cross-cultural comparative studies suggested that sociocultural factors influence symptom reporting in patients with depression; in particular, stigma surrounding mental illness increases the tendency to emphasize somatic symptoms $[14,52]$. We infer from these findings that the difference in helpseeking intentions we observed in this study may be attributed to stigma surrounding mental illness. Many people probably considered dizziness as a symptom arising from physical causes, so that they may not have hesitated to seek help for this health problem.

Depressed mood and insomnia are included in the DSM-5 diagnostic criteria for major depressive disorder
[26]. As a general rule in Japan, people who report these symptoms for over 2 weeks often screen positive for suspected depression. The depressed mood and insomnia problems of this study were intended to present health conditions that require prompt initial contact with healthcare providers. However, more than half of the participants did not choose medical professionals as a potential source of help for these health problems. This result supports the notion that many people with mental disorders tend not to receive professional help or use mental health services [53-56]. A negative perception of the effectiveness of help, a lack of awareness of potential sources of help, and willingness to handle the problem by oneself were the three most frequent reasons for no help-seeking intention. A lack of awareness of potential sources of help was also cited as the most common reason not to seek help from formal sources. In order to increase intentions to seek help from formal sources, policymakers should consider implementing universal interventions such as an education program [16] and an awareness campaign [57] which give all people a better understanding of potential benefits of professional help along with providing information on professional help available to the general public.

As for the depressed mood and insomnia problems, approximately half of the participants gave first priority to seeking help from informal sources, which were two to three times more than those who chose the options of seeking help from formal sources. Moreover, multiple logistic regression analysis revealed that perception of 
family and friends regarding help-seeking was significantly associated with the help-seeking intention from formal sources. As suggested in previous studies, $[58,59]$ family and friends may be regarded more favorably as helpful advisers, so that many people tend to first seek help from them. There is no doubt about the importance of having support from family and friends. However, family and friends may be both a positive and negative influence $[24,58,59]$. If the family and friends have inadequate knowledge about mental illness, their support could be unhelpful or even harmful. In order to increase prompt initial contact with healthcare providers, policymakers should consider improving support from family and friends. Public education campaigns to improve knowledge about mental illness may be adequate to this purpose [60]. Such universal interventions have the advantage of simultaneously targeting both affected individuals and their family and friends.

Multiple logistic regression analysis revealed that the factors significantly associated with help-seeking intentions were almost identical across the four health problems. This result can hardly explain the difference across types of health problems in the likelihood of helpseeking, but it supports the presence of factors associated with help-seeking intentions common to all problem types. In particular, perception of family and friends regarding help-seeking, psychiatric history, contact with people with mental illness, higher HLS-14 scores, and neighborhood communicativeness were significantly associated with the overall help-seeking intention and also the help-seeking intention from formal sources for all the problems of dizziness, insomnia, and depressed mood. Those who have had some exposure to mental illness are less likely to feel reluctant to seek help for mental illness [19-21]. Those who have better health literacy are more likely to acquire exact knowledge of mental illness and apply their knowledge to solving their health problems [44]. Those living in a neighborhood where neighbors say hello whenever they pass each other are more likely to receive the benefit of daily interactions with weak ties (i.e. peripheral members of social networks such as acquaintances) [61, 62]. People who often interact with weak ties, as well as strong ties (i.e. core members of social networks such as family and friends), are more likely to have a sense of belonging and thus less likely to hesitate to seek help from people around them. Besides developing health literacy skills, community-based interventions for creating a friendly approachable atmosphere and facilitating daily interactions with family, friends, and acquaintances may be worth considering as a possible public health strategy for encouraging help-seeking whether for psychological or physical problems. To date, several interventions that focus on facilitating social contact have been reported.
For example, NOCOMIT-J is a community-based multimodal intervention program for suicide prevention in Japan, which set up regional social gatherings to reinforce human relationships in the community [57]. Further studies are needed to determine whether this kind of interventions can be recommended.

This study provides the first step toward understanding the types of health problems for which people intend to seek help. On the contrary, it has a number of potential limitations. First, the study participants were recruited from a nationwide panel of an online research company. As described in the methods section, the study participants included highly educated people twice as many as in the Japanese population. Although we confirmed that the distribution of HLS-14 scores in the study participants was quite similar to that obtained from our previous paper-based survey in Japanese healthcare facilities, [44] the selection bias may have influenced the results to some extent. Second, the webbased survey was self-administered, so that the accuracy of responses must depend on their understanding of questions and their motivation to answer questions accurately. Although the understandability of wording were checked prior to the web-based survey, it is almost impossible to eliminate the information bias completely. Third, the method of measuring help-seeking intentions was based on the most commonly used methodologies, [35-38] but its validity has not been fully confirmed. Respondents were asked to imagine themselves in specified hypothetical health conditions and then report their help-seeking intentions. If some people underestimated the severity of the health problem, the percentage of participants reporting a positive help-seeking intention in this study may have been somewhat different from the actual value. Fourth, the procedure of giving all four health problems to each participant may have affected participants' responses. We cannot deny such influence, but the results of McNemar test indicated that those who thoughtlessly repeated the same responses across four health problems were few, if any. Fifth, because of the cross-sectional design, this study cannot provide definitive evidence of causality. There was no knowing whether the self-reported help-seeking intentions accurately reflect the actual help-seeking behaviors if they become mentally ill. Intention is recognized as a key predictor of behavior, but the strength of the intentionbehavior relationship can vary depending on the type of behavior [63]. The findings of this study should be considered preliminary and need to be confirmed in other populations. In future studies, we intend to examine the relationship between intention to seek professional help and subsequent healthcare service use and elucidate in more detail the difference across types of health problems in the likelihood of help-seeking. 


\section{Conclusions}

The majority of participants indicated their intentions to seek help, but psychological problems (insomnia and depressed mood) were less likely to induce help-seeking than a physical problem (dizziness). A number of individual and neighborhood factors were significantly associated with help-seeking intentions across different problem types. In particular, perception of family and friends regarding help-seeking, psychiatric history, contact with people with mental illness, better health literacy, and neighborhood communicativeness were identified as the factors associated with help-seeking intentions common to all problem types. Besides developing health literacy skills, community-based interventions for creating a friendly approachable atmosphere and facilitating daily interactions with family, friends, and neighbors may be worth considering as a possible public health strategy for encouraging help-seeking whether for psychological or physical problems.

\section{Ethics and consent}

The study protocol was approved by the ethics committee of the Jikei University School of Medicine and has been conducted in accordance with the Ethical Guidelines for Epidemiological Studies by the Japanese Government. Consent to participate was implied by the completion and submission of the survey.

\section{Consent for publication}

There are no details on individual participants within the manuscript.

\section{Availability of data and materials}

The dataset of this study will not be shared because the Ethical Guidelines prohibit researchers from providing their research data to other third-party individuals.

\section{Abbreviations \\ HLS-14: 14-item Health Literacy Scale; LSNS-6: abbreviated Lubben Social Network Scale; RIBS: Reported and Intended Behaviour Scale; WHO-5: World} Health Organization Five Well-Being Index; YLD: year lived with disability.

\section{Competing interests}

The authors declare that they have no competing interests.

\section{Authors' contributions}

MS was responsible for the design and conduct of the study, the collection, analysis, and interpretation of data, and the writing of the article. TY and HS contributed to the data interpretation and discussion of the implications of this work. All authors read and approved the final manuscript.

\section{Acknowledgements}

This work was supported by JSPS KAKENHI Grant Number 25460815. The funder had no role in the design and conduct of the study; in the collection, analysis, and interpretation of data; in the writing of the article; or in the decision to submit it for publication.

\section{Author details}

${ }^{1}$ Department of Public Health and Environmental Medicine, The Jikei University School of Medicine, 3-25-8 Nishi-Shimbashi, Minato-ku, Tokyo
105-8461, Japan. ${ }^{2}$ Center for Suicide Prevention, National Institute of Mental Health, National Center of Neurology and Psychiatry, Tokyo, Japan.

${ }^{3}$ Department of Preventive Medicine, Graduate School of Sports and Health Sciences, Daito Bunka University, Saitama, Japan.

Received: 5 May 2015 Accepted: 2 April 2016

Published online: 07 April 2016

\section{References}

1. Global Burden of Disease Study 2013 Collaborators. Global, regional, and national incidence, prevalence, and years lived with disability for 301 acute and chronic diseases and injuries in 188 countries, 1990-2013: a systematic analysis for the Global Burden of Disease Study 2013. Lancet. 2015;386:743-800

2. WHO World Mental Health Survey Consortium. Prevalence, severity, and unmet need for treatment of mental disorders in the World Health Organization World Mental Health Surveys. JAMA. 2004;291:2581-90.

3. Wang PS, Angermeyer M, Borges G, Bruffaerts R, Tat Chiu W, DE Girolamo G, Fayyad J, Gureje O, Haro JM, Huang Y, Kessler RC, Kovess V, Levinson D, Nakane Y, Oakley Brown MA, Ormel JH, Posada-Villa J, Aguilar-Gaxiola S, Alonso J, Lee S, Heeringa S, Pennell BE, Chatterji S, Ustün TB. Delay and failure in treatment seeking after first onset of mental disorders in the World Health Organization's World Mental Health Survey Initiative. World Psychiatry. 2007;6:177-85.

4. Jorm AF, Korten $A E$, Jacomb PA, Christensen $H$, Rodgers $B$, Pollitt $P$. "Mental health literacy": a survey of the public's ability to recognise mental disorders and their belief about the effectiveness of treatment. Med J Aust. 1997;166:182-6.

5. Jorm AF. Mental health literacy: empowering the community to take action for better mental health. Am Psychol. 2012;67:231-43.

6. Tylee A, Gandhi P. The importance of somatic symptoms in depression in primary care. Prim Care Companion J Clin Psychiatry. 2005;7:167-76.

7. Yap MB, Reavley N, Jorm AF. Where would young people seek help for mental disorders and what stops them?: findings from an Australian national survey. J Affect Disord. 2013:147:255-61.

8. Gibbons RJ, Thorsteinsson EB, Loi NM. Beliefs and attitudes towards mental illness: an examination of the sex differences in mental health literacy in a community sample. PeerJ. 2015;3:e1004

9. Ikegami N, Yoo BK, Hashimoto H, Matsumoto M, Ogata H, Babazono A, Watanabe R, Shibuya K, Yang BM, Reich MR, Kobayashi Y. Japanese universal health coverage: evolution, achievements, and challenges. Lancet. 2011:378:1106-15.

10. Mojaverian T, Hashimoto T, Kim HS. Cultural differences in professional help seeking: a comparison of Japan and the u.s. Front Psychol. 2013;3:615.

11. Jorm AF, Nakane Y, Christensen H, Yoshioka K, Griffiths KM, Wata Y. Public beliefs about treatment and outcome of mental disorders: a comparison of Australia and Japan. BMC Med. 2005;3:12.

12. Simon GE, VonKorff M, Piccinelli M, Fullerton C, Ormel J. An international study of the relation between somatic symptoms and depression. N Engl J Med. 1999:341:1329-35.

13. Simon GE, Goldberg DP, Von Korff M, Ustün TB. Understanding crossnational differences in depression prevalence. Psychol Med. 2002;32:585-94.

14. Patel V. Cultural factors and international epidemiology. Br Med Bull. 2001;57:33-45.

15. Ono Y, Tanaka E, Oyama H, Toyokawa K, Koizumi T, Shinohe K, Satoh K, Nishizuka E, Kominato H, Nakamura K, Yoshimura K. Epidemiology of suicidal ideation and help-seeking behaviors among the elderly in Japan. Psychiatry Clin Neurosci. 2001;55:605-10.

16. Sakamoto S, Tanaka E, Neichi K, Ono Y. Where is help sought for depression or suicidal ideation in an elderly population living in a rural area of Japan? Psychiatry Clin Neurosci. 2004;58:522-30.

17. Kido $Y$, Kawakami N. Sociodemographic determinants of attitudinal barriers in the use of mental health services in Japan: findings from the World Mental Health Japan Survey 2002-2006. Psychiatry Clin Neurosci. 2013;67:101-9.

18. Komiti A, Judd F, Jackson $\mathrm{H}$. The influence of stigma and attitudes on seeking help from a GP for mental health problems: a rural context. Soc Psychiatry Psychiatr Epidemiol. 2006:41:738-45.

19. Jagdeo A, Cox BJ, Stein MB, Sareen J. Negative attitudes toward help seeking for mental illness in 2 population-based surveys from the United States and Canada. Can J Psychiatry. 2009;54:757-66. 
20. Schomerus $\mathrm{G}$, Matschinger $\mathrm{H}$, Angermeyer MC. The stigma of psychiatric treatment and help-seeking intentions for depression. Eur Arch Psychiatry Clin Neurosci. 2009;259:298-306.

21. Mojtabai R. Mental illness stigma and willingness to seek mental health care in the European Union. Soc Psychiatry Psychiatr Epidemiol. 2010;45:705-12.

22. Rüsch N, Evans-Lacko SE, Henderson C, Flach C, Thornicroft G. Knowledge and attitudes as predictors of intentions to seek help for and disclose a mental illness. Psychiatr Serv. 2011;62:675-8.

23. ten Have M, de Graaf R, Ormel J, Vilagut G, Kovess V, Alonso J. Are attitudes towards mental health help-seeking associated with service use? Results from the European Study of Epidemiology of Mental Disorders. Soc Psychiatry Psychiatr Epidemiol. 2010;45:153-63.

24. Albert M, Becker T, McCrone P, Thornicroft G. Social networks and mental health service utilization: a literature review. Int J Soc Psychiatry. 1998:44:248-66.

25. Steele LS, Glazier RH, Lin E. Inequity in mental health care under Canadian universal health coverage. Psychiatr Serv. 2006;57:317-24.

26. Deneke DE, Schultz H, Fluent TE. Screening for depression in the primary care population. Prim Care. 2014;41:399-420.

27. Nakao M, Yano E. Somatic symptoms for predicting depression: one-year follow-up study in annual health examinations. Psychiatry Clin Neurosci. 2006;60:219-25

28. Perlis RH, Fava M, Trivedi MH, Alpert J, Luther JF, Wisniewski SR, Rush AJ. Irritability is associated with anxiety and greater severity, but not bipolar spectrum features, in major depressive disorder. Acta Psychiatr Scand. 2009;119:282-9.

29. Verhoeven FE, Booij L, Van der Wee NJ, Penninx BW, Van der Does AJ. Clinical and physiological correlates of irritability in depression: results from the Netherlands study of depression and anxiety. Depress Res Treat. 2011;2011:126895.

30. Fava M, Hwang I, Rush AJ, Sampson N, Walters EE, Kessler RC. The importance of irritability as a symptom of major depressive disorder: results from the National Comorbidity Survey Replication. Mol Psychiatry. 2010;15:856-67.

31. Suka M, Yamauchi T, Sugimori H. Relationship between individual characteristics, neighbourhood contexts and help-seeking intentions for mental illness. BMJ Open. 2015;5:e008261.

32. Rickwood DJ, Deane FP, Wilson CJ. When and how do young people seek professional help for mental health problems? Med J Aust. 2007;187(7Suppl):S35-9.

33. Clement $\mathrm{S}$, Schauman O, Graham T, Maggioni F, Evans-Lacko S, Bezborodovs N, Morgan C, Rüsch N, Brown JS, Thornicroft G. What is the impact of mental health-related stigma on help-seeking? A systematic review of quantitative and qualitative studies. Psychol Med. 2015;45:11-27.

34. Ministry of Internal Affairs and Communications. National Census 2010. Available at: http://www.e-stat.go.jp/SG1/estat/GL08020103.do?_ toGL08020103_\&tclassID=000001038689\&cycleCode=0\&requestSender=estat [Accessed 1 Oct 2015]. Japanese.

35. Rickwood D, Thomas K, Bradford S. Help-seeking measures in mental health: a rapid review. August 2012 (Sax Institute Evidence Check Library). Available at: https://www.saxinstitute.org.au/publications/help-seeking-measures-inmental-health-a-rapid-review [Accessed 1 Oct 2015]

36. Wilson CJ, Deane FP, Ciarrochi J, Rickwood D. Measuring help-seeking intentions: properties of the General Help-Seeking Questionnaire. Can J Couns. 2005:39:15-28.

37. Oliver MI, Pearson N, Coe N, Gunnell D. Help-seeking behaviour in men and women with common mental health problems: cross-sectional study. $\mathrm{Br}$ J Psychiatry. 2005;186:297-301.

38. Reynders A, Kerkhof AJ, Molenberghs G, Van Audenhove C. Attitudes and stigma in relation to help-seeking intentions for psychological problems in low and high suicide rate regions. Soc Psychiatry Psychiatr Epidemiol. 2014;49:231-9.

39. Meurer WJ, Low PA, Staab JP. Medical and psychiatric causes of episodic vestibular symptoms. Neurol Clin. 2015;33:643-59.

40. World Health Organization Regional Office for Europe. Wellbeing Measures in Primary Health Care: the DepCare Project: Report on a WHO Meeting Stockholm, Sweden 12-13 February 1998. Copenhagen: WHO Regional Office for Europe; 1998

41. Awata S, Bech P, Yoshida S, Hirai M, Suzuki S, Yamashita M, Ohara A, Hinokio Y, Matsuoka H, Oka Y. Reliability and validity of the Japanese version of the World Health Organization-Five Well-Being Index in the context of detecting depression in diabetic patients. Psychiatry Clin Neurosci. 2007;61:112-9.

42. Evans-Lacko S, Rose D, Little K, Flach C, Rhydderch D, Henderson C, Thornicroft G. Development and psychometric properties of the reported and intended behaviour scale (RIBS): a stigma-related behaviour measure. Epidemiol Psychiatr Sci. 2011;20:263-71.

43. World Health Organization. Health promotion glossary, 1998 (WHO/HPR/ HEP/98.1). Available at: http://www.who.int/healthpromotion/about/HPG [Accessed 1 Oct 2015].

44. Suka M, Odajima T, Okamoto M, Sumitani M, Igarashi A, Ishikawa H, Kusama M, Yamamoto M, Nakayama T, Sugimori H. Relationship between health literacy, health information access, health behavior, and health status in Japanese people. Patient Educ Couns. 2015;98:660-8.

45. Suka M, Odajima T, Kasai M, Igarashi A, Ishikawa H, Kusama M, Nakayama T, Sumitani M, Sugimori $H$. The 14-item health literacy scale for Japanese adults (HLS-14). Environ Health Prev Med. 2013;18:407-15.

46. European Union. Mental well-being: special Eurobarometer 248/Wave 64.4, 2006. Available at: http://ec.europa.eu/health/ph_information/documents/ ebs_248_en.pdf [Accessed 1 Apr 2015]

47. DeVellis RF. Scale development: theory and applications. 3rd ed. Thousand Oaks: Sage; 2012.

48. Kessler RC, Ustün TB. The World Mental Health (WMH) Survey Initiative Version of the World Health Organization (WHO) Composite International Diagnostic Interview (CIDI). Int J Methods Psychiatr Res. 2004;13:93-121.

49. Lubben J, Blozik E, Gillmann G, lliffe S, von Renteln Kruse W, Beck JC, Stuck AE. Performance of an abbreviated version of the Lubben Social Network Scale among three European community-dwelling older adult populations. Gerontologist. 2006;46:503-13.

50. Kurimoto A, Awata S, Ohkubo T, Tsubota-Utsugi M, Asayama K, Takahashi K, Suenaga K, Satoh H, Imai Y. Reliability and validity of the Japanese version of the abbreviated Lubben Social Network Scale. Nihon Ronen Igakkai Zasshi. 2011;48:149-57. Japanese.

51. Tsuji I, editor. Health Survey of People Affected by the Great East Japan Earthquake in Miyagi Prefecture (MHLW Grant Research Report 2013). Japanese: Center for Community Health, Tohoku University Graduate Schoo of Medicine; 2014

52. Bagayogo IP, Interian A, Escobar II. Transcultural aspects of somatic symptoms in the context of depressive disorders. Adv Psychosom Med. 2013;33:64-74.

53. Jorm AF, Griffiths KM, Christensen H, Parslow RA, Rogers B. Actions taken to cope with depression at different levels of severity: a community survey. Psychol Med. 2004;34:293-9.

54. Rüdell K, Bhui K, Priebe S. Do 'alternative' help-seeking strategies affect primary care service use?: a survey of help-seeking for mental distress. BMC Public Health. 2008;8:207.

55. Brown J, Evans-Lacko S, Aschan L, Henderson MJ, Hatch SL, Hotopf M. Seeking informal and formal help for mental health problems in the community: a secondary analysis from a psychiatric morbidity survey in South London. BMC Psychiatry. 2014;14:275.

56. Andrade LH, Alonso J, Mneimneh Z, Wells JE, Al-Hamzawi A, Borges G, Bromet E, Bruffaerts R, de Girolamo G, de Graaf R, Florescu S, Gureje O, Hinkov HR, Hu C, Huang Y, Hwang I, Jin R, Karam EG, Kovess-Masfety V, Levinson D, Matschinger H, O’Neill S, Posada-Villa J, Sagar R, Sampson NA, Sasu C, Stein DJ, Takeshima T, Viana MC, Xavier M, Kessler RC. Barriers to mental health treatment: results from the WHO World Mental Health surveys. Psychol Med. 2014;44:1303-17.

57. Ono Y, Awata S, lida H, Ishida Y, Ishizuka N, Iwasa H, Kamei Y, Motohashi $Y$, Nakagawa A, Nakamura J, Nishi N, Otsuka K, Oyama H, Sakai A, Sakai H, Suzuki Y, Tajima M, Tanaka E, Uda H, Yonemoto N, Yotsumoto T, Watanabe N. A community intervention trial of multimodal suicide prevention program in Japan: a novel multimodal community intervention program to prevent suicide and suicide attempt in Japan, NOCOMIT-J. BMC Public Health. 2008;8:315.

58. Griffiths KM, Crisp DA, Barney L, Reid R. Seeking help for depression from family and friends: a qualitative analysis of perceived advantages and disadvantages. BMC Psychiatry. 2011;11:196.

59. Hui A, Wong P, Fu KW. Building a model for encouraging help-seeking for depression: a qualitative study in a Chinese society. BMC Psychol. 2014;2:9.

60. Dumesnil $H$, Verger $P$. Public awareness campaigns about depression and suicide: a review. Psychiatr Serv. 2009;60:1203-13. 
61. Granovetter M. The strength of weak ties: a network theory revisited. Sociol Theory. 1983;1:201-33.

62. Sandstrom GM, Dunn EW. Social interactions and well-being: the surprising power of weak ties. Pers Soc Psychol Bull. 2014;40:910-22.

63. Sheeran P. Intention-behavior relations: a conceptual and empirical review. Eur Rev Soc Psychol. 2002;12:1-36.

Submit your next manuscript to BioMed Central and we will help you at every step:

- We accept pre-submission inquiries

- Our selector tool helps you to find the most relevant journal

- We provide round the clock customer support

- Convenient online submission

- Thorough peer review

- Inclusion in PubMed and all major indexing services

- Maximum visibility for your research

Submit your manuscript at www.biomedcentral.com/submit 